\title{
Dialogic Pedagogies and Multimodal Methodologies: Working Towards Inclusive Science Education and Research
}

\author{
Christina Siry \\ Corresponding author, \\ Institute for Teaching and Learning, Department of Education and \\ Social Work, University of Luxembourg \\ 2, avenue de l'Université, L-4365 Esch-sur-Alzette, Luxembourg \\ christina.siry@uni.lu
}

Received: 27 October 2020 | Revised: 21 November 2020 | Accepted: 30 November 2020

\begin{abstract}
This contribution to the APSE special issue, "Equity and Diversity in Science Education: Implications for the Asia-Pacific Region," presents research on plurilingual students' interactions in science drawn from several studies in the multilingual context of Luxembourg. The goal of the manuscript is to present dialogic pedagogies and multimodal methodologies as central to working towards equitable practices in science education, in particular when working with culturally and linguistically diverse students. Through a layering of claims from prior case studies, the manuscript makes three assertions: multimodal methodologies highlight children's embodied participation in science; multimodal methodologies support resource-rich perspectives on children; and dialogic pedagogical structures mediate children's engagement of resources. An interpretive discussion focuses on the necessity of situating difference as a resource, and implications are raised for science education teaching and research.
\end{abstract}

\section{Keywords}

early childhood science education - elementary/primary science education resource-rich perspectives - plurilingual students - multilingual contexts - equity and diversity 
The purpose of this manuscript is to explore dialogic, open-ended pedagogies as inclusive approaches to science education at the early childhood and elementary levels, in particular as critical for working with linguistically diverse students. Aligned with the theme of this special issue in APSE, "Equity and Diversity in Science Education: Implications for the Asia-Pacific Region," I look across several studies conducted within my research team in the multilingual ${ }^{1}$ context of Luxembourg to illustrate the value of providing time and space for children to engage in science inquiry, and to reflect upon the inherent complexities of children's science learning. I weave together understandings gleaned from several different research studies that have examined plurilingual students' interactions in science, with a goal of presenting dialogic approaches to science education as central to working towards equitable practices. This manuscript layers together claims from previous studies conducted in my research team that utilized multimodal methodologies to examine children's interactions while participating in science. Through an unfolding of the claims drawn from three case studies, I draw assertions and implications for science education in diverse contexts, both in the Asia-Pacific region and beyond. The following sections provide context for understanding the multimodal ways in which children engage in science, by discussing how dialogic pedagogical approaches and multimodal methodologies come together to both deepen and broaden what we are learning about the nuances of science education.

Guiding Frameworks and Context

\subsection{Science as Cultural Enactment}

My research begins from the assumption that science is enacted as culture, and, as such, science education is a cultural practice, one that is embodied, embedded in, and emergent from children's interactions around science phenomena. I am guided by William Sewell's (1999) theorization of culture as being enacted as patterns of practices and schema, and these patterns have thin coherence and are interconnected with contradictions. I draw inspiration from scholars who position science as cultural enactment (e.g., Roth \& Lawless,

1 Following the Council of Europe (2018), I use the term multilingual to refer to contexts in which different languages are used side by side and plurilingual to refer to speakers. Plurilingualism as a concept emphasizes the blended, hybridized ways in which communication occurs across different communicative resources such as languages. 
2002; Tobin, 2015a; Tobin \& Ritchie, 2012) and see science education as a form of culture with its own narrative forms, material practices, and beliefs. Science learning emerges from critical engagement with knowledge and experience as tools for making sense of the world in culturally and socially relevant ways. I research science education at the primary levels in the multilingual context of Luxembourg, and the work that my research team and I engage in seeks to highlight the diversity of ways that young children participate in science. Through the lenses that ground our work, learning science is both individual and collective and is based on situated (re)negotiation of meaning in the world through experiences. Such sociocultural orientations allow for focusing on the social, material, and temporal aspects of learning science (Cowie \& Otrel-Cass, 2011).

Through numerous studies in different classroom contexts, we have examined the ways that young children engage in science, which is conceived of as embodied engagement in phenomena, a process that is done in interaction (e.g., Siry, Ziegler, \& Max, 2012). We are learning about the ways in which science understandings and related skills emerge from this "doing" of science, and the notion of emergent science (Siraj-Blatchford, 2001) guides our perspectives on science learning in primary schools. Emergent science as a grounding concept shifts the focus of learning from "conceptual understanding of a predetermined teaching content to science as a social practice" (Günther-Hanssen, 2020, p. 888-889). The practice of science is a socially situated phenomenon, and through the cultural enactment of science as practice, new understandings about science emerge as students engage in interaction with peers and teachers. Because children's knowledge emerges in a continuous and complex process, we work towards dialogic structures for children to express and pursue their wonderings as they participate in doing science.

\subsection{Dialogic Pedagogies with Young Children}

Education through the lenses we bring to our work is grounded in reciprocity and dialogue as participants come together in interaction to articulate their ideas, wonderings, and knowledges. My team and I seek to understand and valorize the complexities of what young students can know, do, and wonder, and as such, we work towards dialogic approaches to pedagogy that provide opportunities to participate in science in open-ended ways. Working towards dialogic interactions as pedagogy serves to "engage children, stimulate and extend [children's] thinking, and advance their learning and understanding" (Alexander, 2003, p. 35). Dialogic approaches are relational, as dialogue 
is much more than the words that might be used as people communicate (Bakhtin, 1981): It is a fundamental orientation to the Other, and thus the basis for relationship (Shields, 2007). A dialogic classroom environment is recipro$\mathrm{cal}$, as teachers and children listen to each other and exchange meanings, recognizing that meanings are contextualized and multiple.

The sections that follow highlight findings from research that examined the role of open-ended pedagogies, in particular through examining interactions of culturally and linguistically diverse students as they engaged in inquiry. Dialogic approaches allow for orienting towards inquiry (Shields, 2007), and, relatedly, an inquiry orientation to curriculum supports dialogic interactions (Wells \& Ball, 2008). Inquiry-based approaches facilitate children's investigations in dialogic ways, as questions, wonderings, and investigation foci emerge from interactions between children. Dialogic approaches can shed light on children's understandings of natural science phenomena and support building on students' understandings in science teaching (Siry, Brendel, \& Frisch, 2016). Further approaches of this kind can provide experiences related to science concepts that can be linked to children's sense of wonder about their own environments (Baldwin, Adams, \& Kelly, 2009). Herein I elaborate the ways in which dialogic approaches can mediate young children's engagement in science in ways that are not linguistically bound and that shine light on the many resources young children bring to science education. In doing so, I seek to make the argument that highlighting, valuing, and building upon students' diverse resources is an inclusive approach for science education that can mediate working towards equitable classroom practices, in particular in highly diverse contexts.

\subsection{Luxembourg as a Superdiverse Research Context}

The research that follows was conducted in the European country of Luxembourg, a small country with a total population of just over 625,000 in 2020 and an area of roughly $2,500 \mathrm{~km}^{2}$. Despite its small size, Luxembourg has one of the highest population densities in Europe ${ }^{2}\left(242 / \mathrm{km}^{2}\right)$ as well as the highest density of non-national residents in Europe, coupled with one of the highest population growth rates in Europe. There are over 170 nationalities in Luxembourg, and this diversity is also reflected in the public schools, in which $49 \%$ of students hold nationalities other than Luxembourgish and $63.5 \%$ of students speak primary languages at home other than Luxembourgish (MENJE,

2 For comparison to the Asia-Pacific region: South Korea has $512 / \mathrm{km}^{2}$, Japan has $335 / \mathrm{km}^{2}$, Philippines has $320 / \mathrm{km}^{2}$ (worldpopulationreview.com). 
2019). The linguistic diversity inherent in Luxembourg's primary classrooms is at the core of our research projects, as we explore the ways in which communicative resources come together in science classroom contexts and how access to diverse resources can mediate young children's meaning making in science.

A contextual consideration in Luxembourg is that the school system is trilingual, meaning that at the primary levels, in which our work is carried out, the curriculum is taught in Luxembourgish, German, or French, depending on grade level and subject area. Children attend primary school in 2-year cycles, and kindergarten (Cycle 1, ages 4-6) is mandatory, with Luxembourgish as the curricular language of communication. In Cycle 2 (ages 6-8), German is introduced as the main language of instruction. Children learn to read and write in German, and most subjects are taught in German, until French is introduced as a further language at the end of Cycle 2. There is an expectation that children will be fluent in all three languages by completing primary school at the end of Cycle 4 (age 12). For children coming to school speaking Luxembourgish, the additional two languages can already be challenging, as children learn basic literacy in German at the same time as they learn the German language, and for children with other language backgrounds, it is even more challenging (Mauro-Hetto, 2009). The national curriculum dictates that science as a subject area is to be instructed in Luxembourgish at the Cycle 1 level and in German beginning in Cycle 2. This results in many children in Luxembourg's primary classrooms learning science in a language that they are also learning at the same time.

\subsection{Researching Young Children's Science Investigations}

My research agenda is guided by a goal of working towards ways to co-construct science learning opportunities that build from children's perspectives, experiences, and wonderings. My team and I work towards this goal across multiple projects, each revealing different facets of children's engagement in science that, when considered together as they are in the sections that follow, serve to emphasize an overarching perspective on the multiplicity and diversity of resources that students bring to science interactions, and the value of providing space and time for children to engage in open-ended investigations. The body of research undertaken over time in our team has examined young children's science investigations in different classroom contexts and through different theoretical lenses, and by unpacking and connecting claims from previous research, I intend to explore how the methodologies used in research can highlight resources that linguistically diverse students bring to the classroom 
and how dialogic science education pedagogies can position children to build upon these resources as they participate in science.

In the sections that follow, I trace the evolution of understandings gleaned from several of my team's recent studies, each grounded in working towards gaining new understandings of the intricacies of science education in multilingual contexts. I elaborate the methodologies that have guided our examinations of students' and teachers' interactions, with a goal of highlighting what we are learning within the different studies, and, in particular, across the studies, with an eye on implications for teaching practice and future research and with a focus on inclusive approaches for early childhood science education.

\subsection{Evolving Methods to Examine Multimodal Interactions}

Critical ethnography (e.g., Carspecken, 1996) extends through most of the work we engage in, as we seek to gain understandings of the contextually specific ways in which children interact around science. Critical ethnography moves beyond the ethnographic question of "what is happening?" to ask the question of "why is it happening?" These are two central questions for engaging in interpretive research (Tobin, 2015b), and in working towards addressing these questions, our methodologies guide us as we search for patterns of both coherence and associated contradictions. Based on these questions, a focus for analysis emerges, typically with the creation of a single case study, several examples of which follow. Case study research (Stake, 1995) allows for "the study of the particularity and complexity of a single case, coming to understand its activity within important circumstances" (p. xi). Because we strive to understand the contextually bounded ways in which children engage in science education, and adopt a flexible approach to the use of case studies in our team to place the focus on "what is studied (the case) rather than how it is studied (the method)" (Harrison, Birks, Franklin, \& Mills, 2017, para. 11). As such, the methods adopted shift and change with each study, allowing for studying the peculiarity as well as the complexity of the individual case within context.

Multimodal theorizations through social semiotic lenses (e.g., Jewitt, Kress, Ogborn, \& Tsatsarelis, 2001; Jewitt \& Kress, 2003) focus on meaningmaking and allow for examining the ways in which meanings are made with ensembles of modes, including gestures, speech, objects, images, gaze, body position, actions, facial expressions, and writing (Bezemer, Diamantopoulou, Jewitt, Kress, \& Mavers, 2012). Each mode offers specific potential for communication. We have refined a method of multimodal interaction analysis over time that has supported examining students' and teachers' communicationin-situation with the aim of gaining new understandings about plurilingual 
students' participation in science practices, and the details of this methodological approach have recently been elaborated elsewhere (Wilmes \& Siry, accepted). Video analysis with a focus on valorizing the non-verbal can reveal communicative resources that might be obscured by analysis that is rooted in the verbal (Wilmes, Siry, Gomez Fernandez, \& Gorges, 2018); therefore, we typically engage in an iterative analytic process of moving between the nonverbal and verbal, with the entry point into the data being dependent upon the emergent focus.

Science is an embodied and discursive practice, and multimodal interaction analysis supports examining this process. Early childhood science education is inherently complex (Fragkiadakis, Fleer, \& Ravanis, 2020), and we have utilized different approaches for examining students' interactions multimodally, with a central focus on valuing the students' non-verbal participation. Multimodal approaches can serve to situate and provide help in understanding the ways in which communication takes place across and within different modalities, which include language among many others (Jaipal, 2009). Video serves as a main data resource across the studies drawn upon herein, together with relevant artifacts to diversify the data resources, such as field notes, written reflections, and student notebooks (Wilmes \& Siry, 2020). Multimodal transcripts (Siry, Ziegler, \& Max, 2012) are constructed, and these take different forms, as the specifics of what is included in these emerge and develop based upon the particular study. The recursive and iterative process of creating and re-creating multimodal transcripts refines the foci further, and we examine data resources to discover patterns and contradictions. This results in the multimodal analytic approaches we adopt being multilayered, emerging and evolving as each study unfolds. Compared to language-based analytic lenses, multimodal lenses provide a wider perspective for working towards an understanding of students' engagement in science practices.

\section{Weaving Together Different Case Studies}

Several strands of research come together to provide a lens for understanding the role of dialogic structures in science education with young children, and this section builds from three studies, each with differing foci. What is common across the studies is the focus on examining the ways in which plurilingual children engage in science investigations and related interactions, in particular those that are learning the languages of instruction. I weave together points drawn from these prior studies to focus specifically on multimodal methodologies in order to unpack how these can reveal nuances about 
science participation that might not be visible in research that uses languagebased analytic lenses, including the many resources that children draw on in interaction. As I explore the development of the use of such methodologies in our work, I elaborate how multimodal analysis can highlight the differing embodied ways in which children engage in doing science. Through several case studies of young children's interactions presented in the next sections, I intend to show how multimodal methodologies have allowed for exploring children's embodied practices of science and emphasize how young plurilingual students' engagement in science has become visible in ways beyond what is spoken or written.

\subsection{Multimodal Methodologies Highlight Children's Embodied Participation}

Research examining plurilingual students' participation in inquiry-based science in multilingual classrooms in Luxembourg has revealed a diversity of foci regarding the complex ways in which children engage in doing science, and this diversity has led to drawing on different analytic frameworks. In one recent study (Gomez Fernández \& Siry, 2018) we considered the role of identities within the doing of science in a third-grade class, using multimodal methods to examine a plurilingual student named Pedro's participation within a small group in his class. Pedro's class participated in a five-lesson unit on environmental protection, and we focused our analysis on one lesson centered around a water-filtering investigation. Pedro's teacher used Luxembourgish for oral communication and German for writing tasks, which is a common practice in primary classrooms. Pedro was selected as the focal case because he initially appeared disengaged in the science investigations and related interactions, and we noted that he appeared to lack confidence in speaking German and copied from other students when he needed to write in German. He worked as part of a small group during the science lessons, and while the peers in his group were able to draw on their home language of Luxembourgish in their interactions with each other and around the investigation and related worksheets, he was not able to use his home language of Portuguese for making meaning with his peers. Analysis focused on changes in embodiment and participation, through a focus on changes in his footing (Goffman, 1981), which is "the alignment we take up to ourselves and the others present as expressed in the way we manage the production or reception of an utterance" (p. 128). Multimodal analysis in this case revealed how Pedro's positioning within the small group changed depending on the science task. Examining his position relative to both the materials and his peers revealed the ways in which Pedro's participation shifted within his group, from a peripheral role to a more central one when positioned to take 
on the role of leader in his group. Relatedly, analysis also showed that when he needed to complete written work that required one correct answer, his footing suddenly changed again and he was passive and participated only peripherally. His shift in footing mediated his participation in investigations, as his embodied participation increased when he was positioned to engage actively with materials as opposed to when a task was focused on writing.

A student's embodied participation was the focus of a different study from our team (Wilmes \& Siry, 2018), in which interaction ritual theory (Collins, 2004) served as a methodological lens to examine the case of a plurilingual student named Teo as he participated in small group inquiry. Teo was selected as a case because we had observed that he did not verbally participate in wholeclass discussions in German and that when he passed the video cameras he often stopped to speak briefly in French into the cameras. Further, he had mentioned to us that he mostly spoke French outside of school, including at home. And lastly, his teacher had noted that he had weak proficiency in German and was thus at risk of repeating the year. Because we were interested in learning more about Teo's engagement with science and with his peers in small groups, we turned to interaction ritual theory (Collins, 2004) to ground the case study. Interaction ritual theory positions social interaction as the foundation of social life, and Collins theorizes that rituals occur when people come together to collectively engage in a task. Through shared focus and the mutual engagement in a joint task, there can be a synchrony that forms in movements and speech, and this synchrony occurs on the microlevel and thus is often imperceptible in the moment. Analysis over time revealed changes in Teo's interactions as the class participated in a series of inquiry-based investigations. Multimodal analysis showed that at the beginning of the unit, he stood behind his group members, and his engagement was asynchronous to that of his peers. He often looked over their shoulders at the investigation and did not directly manipulate any materials. Microanalysis revealed how through successful positive interactions over time, synchrony developed in the small groups that Teo worked with over 6 months, and through a build up of positive emotions over time, Teo not only took on a more central role in the investigation, but also initiated conversation with teachers in German.

This study and the study of Pedro were guided by a desire to learn more about the ways in which plurilingual children participate in science when they are also learning the languages of instruction. Pedro and Teo's embodied, often silent, participation became visible through multimodal analytic approaches that started first with the non-verbal. This allowed for highlighting forms of participation that might otherwise go unnoticed if the analysis were to be 
primarily based on verbal interaction. The focus in many classrooms in our context often being on the written and spoken aspects of science instruction can risk marginalizing children who are learning in languages that they are at the same time also still learning. We hope to instead foreground the ways in which science is done in interaction, and, by doing so, shine a light on the many resources, often non-verbal, that young children bring to science in order to draw implications for science instruction.

\subsection{Multimodal Methodologies Support Resource-Rich Perspectives on Children}

I seek to push back on perspectives that position language learners through deficit lenses, and my team and I have endeavored to utilize a variety of methods and methodologies to highlight the diverse ways that these children engage in science inquiry. Multimodal methodologies allow for exploring the embodied ways in which children such as Teo engage in science, and in doing so, they can support rich perspectives on the many resources that children bring to science. Teo utilized a variety of non-verbal and verbal communication resources, and interaction ritual analysis revealed layers of interaction that might have been missed with language-based lenses. The analysis considered how Teo was positioned to engage both silently and verbally in science practices and employ diverse linguistic resources in interaction. Microanalysis enabled examining non-verbal aspects of Teo's interaction that may not have been evident in real time, and, layered with meso-analysis, the microanalysis led to an understanding of his language use and participation in science practices. Multimodal analysis showing his body position, facial expressions, and gestures revealed the ways in which student-driven, inquiry-based science instruction mediated his engagement as he built successful positive interaction rituals through strategies such as silent participation through close observation, intense listening, and mirroring. It was evident that there was both an increase in his participation in science over time as well as his use of spoken German.

In a study of a kindergarten class engaging in science investigations on the topic of sound (Siry \& Gorges, 2020), a case study of a plurilingual student named Katrina examined the ways in which her science understandings became evident in dialogue after she participated in inquiry-based investigations. Katrina was selected as a case because she was a recent newcomer to Luxembourg and was learning Luxembourgish, and we were interested in the different resources she drew on when positioned within open-ended structures to share her experiences and meanings from a class investigation around the topic of sound. Her class had participated in a lesson in which 
glass bottles were filled with different levels of water, and the children investigated the ways in which they could produce different pitches and volumes of sounds from blowing over and into the bottles. After the children's open-ended investigations, multimodal analysis examined the ways Katrina explained her understandings in two different classroom settings: a wholeclass presentation guided by questions from her teacher and an open-ended dialogue earlier with a researcher. There was a dual focus that emerged through this study, as we investigated the resources that she drew on in her explanations and how the structures at hand shaped the resources she could use in these explanations.

Multimodal analysis showed how an open-ended dialogic structure of classroom interaction mediated her agency in meaning making, as she engaged and moved between numerous resources, and her explanation revealed a more complex understanding of the investigation than her retelling during a whole-class presentation later. More specifically, in a presentation to her classmates, Katrina sat on a chair facing her peers and the teachers, as her teacher asked her to explain what happened in the sound investigation. She held her hands in her lap for much of the interaction, and hesitantly described parts of the investigation, such as uttering that the water had been colored blue, after another child had called out the word blue. The question-and-answer exchange between Katrina and her teacher led to a summary of information about what was done, but there was no discussion of the ways in which sound was produced or the role of the glass bottle, blowing the air, or the level of water, and it was not evident through the exchange that Katrina had understood the overarching foci of the investigation. When this episode was analyzed, we turned back to the data resources and noted that in an earlier, more informal dialogue with a researcher, Katrina had revealed a much more complex understanding of the processes from which the sound emerged. Multimodal analysis highlighted the ways in which she used her own drawn documentation of the investigation as well as her body to discuss how the air came from her mouth to produce sounds with the bottle. She stood up and moved around the space as she demonstrated how she was able to make sound previously by blowing over the top of the bottle. In this explanation, she used an imaginary bottle to demonstrate how her mouth was positioned in order to create sound, and she used gestures, sounds, words, and facial expressions to explain how the air came from her mouth and into and over the bottle. Because Katrina used multiple resources in this exchange that had not been available to her during the whole-class presentation, her whole-class explanation did not reveal as much complexity about her understandings of the investigation. Access to a wide range of resources in interaction with the researcher led to a more nuanced 
and conceptually oriented explanation of the science phenomena than when seated in front of the class in a presentation format.

Across these studies, multimodal methodologies revealed communicative, social, and cognitive resources that were not revealed through speech and provided lenses to examine the ways in which Pedro, Teo, and Katrina engaged that might have otherwise gone unnoticed.

\subsection{Dialogic Structures Mediate the Engagement of Resources}

Dialogic pedagogical approaches bring a focus on the social and relational aspects of learning and can highlight the different ways that children engage in science while also bringing together different understandings. Engaging with materials allowed for Pedro's movement to becoming a more active participant within a science activity (Gomez Fernández \& Siry, 2018). Analysis revealed how he was initially only peripherally engaged with any tasks that involved reading and writing, but through a playful embodied engagement with materials, Pedro was able to move to a more central position, and he assumed leadership in his group by opening up the structure of the science task. Open-ended structures enabled Teo to experience positive emotions over time that positioned him to be a more central participant (Wilmes \& Siry, 2018). Collins (2004) details how humans seek out interactions in ways that generate positive emotions and shows that if these positive emotion-generating interactions are repeated, the results can lead to entrainment and synchrony in a group in the short term and solidarity over the long term. The open-ended nature of the inquiry-based science lessons provided space and time for Teo to engage a variety of diverse communicative resources, which over time led to the emergence of positive emotional energy. The micro- and meso-analysis reveal how Teo's engagement in doing science increased while the inquiry-based pedagogies also allowed Teo to form successful interaction rituals, which over time led to increased participation coupled with increased communication in spoken German. Thus, over time participation in dialogic pedagogical structures supported Teo in developing the classroom language of literacy.

In comparison to the analyses of Pedro and Teo and their positioning relative to a small group of peers, analysis of Katrina focuses on two different classroom formats, whole-group presentation and informal dialogue, and reveals a contrast that arises between ways in which she is positioned in a whole-class presentation versus a conversation with a researcher in which she draws upon wider range of communicative resources (Siry \& Gorges, 2020). Our studies come together to reinforce the value of open-ended structures for working with language learners, as such dialogic structures afford these language learners opportunities to engage in science practices that in turn allow for engaging 
diverse resources in demonstrating and developing their science explanations and understandings. Open-ended science investigations and dialogue are structures that can provide space for communicative complexity. The importance of space and time become clear, as open-ended structures provide opportunity for both flexible participation and resource use as students pursue their own wonderings. Open-ended science education approaches that are grounded in dialogue can provide space for plurilingual students to develop their science identities while also developing their language competencies (Wilmes, Siry, Gomez Fernandez, \& Gorges, 2018).

With each of these studies, analysis focused on cases of individual children and their interactions with each other, their teachers, and materials. Each has shone a different light on the ways in which young plurilingual children engage in doing science. Multimodal analysis supports understanding how these language learners employ communicative resources while engaging in inquiry-based science. Individual case studies have provided a deep view into children's participation and engagement in science learning, and bringing them together allows both patterns and contradictions to be revealed, each of which provide new understandings.

Implications and Closing Thoughts

Understanding the complexities of the multimodal ways in which children engage in making meaning in science has implications for teaching and research, and the implications of this work extend beyond Luxembourg. While our context is unique, it is also representative of the shifts that classrooms in other international contexts are experiencing, as the number of students who speak languages in addition to or other than the language of instruction increases globally (e.g., Camarota, 2007). In particular the assertions raised in this paper are relevant for settings in which students are learning the language of instruction, whether in monolingual or multilingual contexts, as they emphasize the role of open-ended dialogic approaches for positioning children to participate in science in ways that are not only bound to language.

There are implications that can be drawn to readers in the Asia-Pacific region, in particular for those working in national contexts that have bi- or multilingual educational policies. In such contexts, students may likely be learning science in languages that they are at the same time also learning, and multimodal methodologies and dialogic pedagogies can highlight and provide space for the vast resources students bring to science. A recent paper 
published in this journal (Williams, Tang, \& Won, 2019) elaborated issues that English Language Learners face in Hong Kong's bilingual English immersion. The research examined the ways in which multimodal instructional teaching supported students as they shared and refuted ideas around science and collaboratively constructed understandings in multimodal dialogue.

Diversity implies difference, and a dialogic approach requires remaining open to difference, acknowledging it, and building from it. The examples drawn on in this manuscript relate to differences in languages, and the analyses have revealed the diverse ways these children engaged that might have gone unnoticed with different methodological lenses. There is a diversity of differences, aside from the linguistic ones, and these are not to be seen as deficits, but rather as an indication of the richness that can be revealed and furthered in dialogue. A dialogic environment is reciprocal, as teachers and children listen to each other, exchange ideas, and consider alternative perspectives (Monteira \& Jiménez, 2016). Dialogue is not only talk, but rather it is a way of engaging diversity and developing new understandings.

The single most important action a teacher can take to shift the interaction from monologic to dialogic is to ask questions to which there are multiple possible answers, and then to encourage the students who wish to answer to respond to, and build upon, each other's contributions. (Wells \& Mejía Arauz, 20o6, p. 414)

A dialogic approach is grounded in understanding the multiplicities of possibilities for engaging in science and is based on difference and multiple perspectives; thus, a dialogic stance requires acknowledging the plurality of experiences and encouraging multiple ways of knowing. A pedagogy built on dialogue is a pedagogy based on difference. Difference ought to be situated as a resource rather than pathologized (Shields, Bishop, \& Mazawi, 2005) or positioned as a deficit to be overcome. There are myriad differences and countless ways to be diversity is richness, especially when it grounds education. Children come to school with diverse experiences and rich funds of knowledge that can serve as important resources to science learning. Working towards equity requires providing opportunities for children to build on these resources in ways that are meaningful for them. Dialogic, open-ended approaches to science education can serve as inclusive approaches to science education, as children are positioned to build from what they know and wonder.

The culture that is science learning is enacted, and emergent from interactions. Our research seeks to highlight the complex and highly embodied ways in 
which children engage in science. The multimodal perspective draws attention to that which is not (yet) curricularized (Bezemer, Diamantopoulou, Jewitt, Kress, \& Mavers, 2012, p. 13). Multimodal methodologies allowed for in-depth examination of the embodied nature of Pedro's, Teo's, and Katrina's science engagement, and when individual cases such as these are layered together, there is a small glimpse of the immense complexities of young children's science practices. Uncovering, highlighting, and respecting the diversity of ways in which children engage in science can become a starting point for reframing science pedagogy and practice at the early childhood and elementary levels as an embodied search for making meaning.

\section{Ethical Considerations}

The research studies reported herein were each reviewed and approved by the Ethics Review Panel of the University of Luxembourg. The data resources collected and drawn on in this paper had obtained the necessary clearance from guardians and assent from students involved in the studies. In order to protect the identities of all participants, pseudonyms were used.

\section{About the Author}

Christina Siry is Professor of Learning and Instruction and head of the Institute for Teaching and Learning at the University of Luxembourg. Her work is grounded in critical theoretical approaches and her research focuses on plurilingual children's interactions as they participate in science. She is Co-Editor of the journal Cultural Studies of Science Education, and has recently guest coedited a special issue in the International Journal of Science Education focused on international perspectives on science education in multilingual contexts.

\section{References}

Bakhtin, M. (1981). The dialogic imagination: Four essays (C. Emerson, Trans., M. Holquist.). Austin, TX: University of Texas Press.

Baldwin, J. L., Adams, S. M., \& Kelly, M. K. (2009). Science at the center: An emergent, standards-based, child-centered framework for early learners. Early Childhood Education Journal, 37(1), 71-77. 
Bezemer, J., Diamantopoulou, S., Jewitt, C., Kress, G., \& Mavers, D. (2012). Using a social semiotic approach to multimodality: researching learning in schools, museums, and hospitals. National Centre for Research Methods Working Paper.

Carspecken, P. (1996). Critical ethnography in educational research: A theoretical and Practical guide. New York, NY: Routledge.

Collins, R. (2004). Interaction ritual chains. Princeton University Press.

Council of Europe (2018). Common European Framework of Reference for Languages: Learning, teaching, assessment. Companion volume with new descriptors. Strasbourg: Council of Europe. Retrieved from https://www.coe.int/en/web/ common-european-framework-reference-languages.

Cowie, B., \& Otrel-Cass, K. (2011). Exploring the value of 'horizontal' learning in early years science classrooms, Early Years, 31(3), 285-295.

Fragkiadakia, G., Fleer, M., \& Ravanis, K. (2020). Understanding the complexity of young children's learning and development in science: A twofold methodological model building on constructivist and cultural-historical strengths. Learning, Culture, and Social Interaction. doi:10.1016/j.lcsi.2020.100461.

Goffman, E. (1981). Forms of talk. Philadelphia: University of Philadelphia Press.

Gomez Fernández, R. \& Siry, C. (2018). “Opening up” a science task: An exploration of shifting embodied participation of a multilingual primary student. International Journal of Science Education, 40(7), 771-795.

Günther-Hanssen, A. (2020). A swing and a child: How scientific phenomena can come to matter for preschool children's emergent science identities. Cultural Studies of Science Education. doi:10.1007/s11422-020-09980-w.

Harrison, H., Birks, M., Franklin, R. \& Mills, J. (2017). Case study research: Foundations and methodological orientations [34 paragraphs]. Forum Qualitative Sozialforschung/Forum: Qualitative Social Research, 18(1), Art. 19, http://nbn -resolving.de/urn:nbn:de:o114-fqs1701195.

Jaipal, K. (2009). Meaning making through multiple modalities in a biology classroom: A multimodal semiotics discourse analysis. Science Education, 94(1), 48-72. doi:10.1002/sce.20359.

Jewitt, C., Kress, G., Ogborn, J. \& Tsatsarelis, C. (2001). Exploring learning through visual, actional and linguistic communication: the multimodal environment of a science classroom. Educational Review, 53(1), 5-18. doi:10.1080/00131910123753.

MENJE. (2019). Les chiffres clés de l'éducation nationale: Statistiques et indicateurs $2017 / 2018$ (Key numbers of national education: Statistics and indicators 2017/2018). Luxembourg.

Monteira, S. F. \& Jiménez-Aleixandre, M. P. (2016). The practice of using evidence in Kindergarten: The role of purposeful observation. Journal of Research in ScienceTeaching, 53(8), 1232-1258. doi:10.1002/tea.21259. 
Roth, W-M., \& Lawless, D. (2002). Science, culture, and the emergence of language. Science Education, 86(3), 368-385.

Sewell, W. (1999). The concept(s) of culture. In V. Bonnell \& L. Hunt [Eds.] Beyond the cultural turn: New directions in the study of society and culture (pp.76-95). Berkeley: University of California Press.

Shields, C. (2007). Bakhtin Primer. Peter Lang.

Shields, C., Bishop, R. \& Mazawi, A. (2005). Pathologizing practices: An overview. Counterpoints, $268,1-22$.

Siraj-Blatchford, J. (2001). Emergent science and technology in the early years. Scientifc and Technological Education for Small Children. Santiago: XXIII World Congress of OMEP.

Siry, C., Brendel, M., \& Frisch, R. (2016). Radical listening and dialogue in educational research. International Journal of Critical Pedagogy, 7(3), 120-136.

Siry, C., \& Gorges, A. (2020). Young children's diverse resources for meaning making in science: Learning from multilingual contexts. International Journal of Science Education, 42(14), 2364-2386. doi:10.1080/o950o693.2019.1625495.

Siry, C., Ziegler, G., \& Max, C. (2012). "Doing science” through discourse-in-interaction: Young children's science investigations at the early childhood level. Science Education, 96, 311-326. doi:10.1002/sce.20481.

Stake, R. E. (1995). The art of case study research. Thousand Oaks, CA: Sage.

Tobin, K. (2015a). The sociocultural turn in science education and its transformational potential. In C. Milne et al. (eds.), Sociocultural Studies and Implications for Science Education (pp. 3-31). Rotterdam: Springer.

Tobin, K. (2015b). Connecting science education to a world in crisis. Asia Pacific Science Education, 1(2). doi:10.1186/s41029-015-0oo3-Z.

Tobin, K., \& Ritchie, S. (2012). Multi-method, multi-theoretical, multi-level research in the learning sciences. The Asia-Pacific Education Researcher, 21(1), 117-129.

Wells, G., \& Meíja Arauz, R. (20o6). Dialogue in the classroom. Journal of the Learning Sciences, 15(3), 379-428. doi:10.1207/s153278o9jls1503.

Wells, G., \& Ball, T. (2008). Exploratory talk and dialogic inquiry. In N. Mercer \& S. Hodgkinson [Eds.] Exploring talk in school: Inspired by the work of Douglass Barnes (pp. 167-184). London: Sage.

Williams, M., Tang, K-S., \& Won, M. (2019). ELL's science meaning making in multimodal inquiry: A case-study in a Hong Kong bilingual school. Asia-Pacific Science Education, 5(3). doi:10.1186/s41029-019-0031-1.

Wilmes, S., \& Siry, C. (accepted). Multimodal Interaction Analysis: a powerful tool for examining plurilingual students' engagement in science practices. Research in Science Education. 
Wilmes, S., \& Siry, C. (2020). Science notebooks as interactional spaces in a multilingual classroom: Not just ideas on paper. Journal of Research in Science Teaching, 57(7), 999-1027. doi:10.1002/tea.21615.

Wilmes, S., \& Siry, C. (2018). Interaction rituals and inquiry-based science instruction: Analysis of student participation in small-group investigations in a multilingual classroom. Science Education, 102(5), 1107-1128. doi:10.1002/sce.21462.

Wilmes, S. E. D., Siry, C., Gomez Fernández, R., \& Gorges, A. (2018). Underscoring the value of video analysis in multilingual and multicultural classroom contexts. The Video Journal of Education \& Pedagogy, 3(4). doi:10.1186/s4099o-018-oo16-o. 